\title{
The genetic basis of male sterility in Schiedea (Caryophyllaceae), an endemic Hawaiian genus
}

\author{
STEPHEN G. WELLER \& ANN K. SAKAI \\ Department of Ecology and Evolutionary Biology, University of Calffornia, trvine, CA 92717, USA
}

\begin{abstract}
Interspecific crosses of Schiedea and Alsinidendron (Caryophyllaceae), endemic Hawaiian genera, produced segregation patterns of females, males, and hermaphrodites consistent with nuclear control of male sterility. Female excesses, typical in hybrids when mismatches occur between cytoplasmic factors controlling male sterility and nuclear factors restoring fertility, were not observed in any crosses. The nuclear gene controlling expression of the male (or hermaphroditic) sex in Schiedea is dominant; females are homozygous recessives. Results from intraspecific crosses and segregations among progeny raised from field-collected seeds were largely consistent with results obtained from interspecific and intergeneric crosses. In Schiedea gynodioecy is likely to represent an early stage in the evolution of dioecy. The transition from gynodioecy to full dioecy may be a relatively rapid event favoured by nuclear control of male sterility, a view supported by the occurrence of gynodioecy, subdioecy, and dioecy in Schiedea.
\end{abstract}

Keywords: dioecy, gynodioecy, Hawaii, male sterility, Schiedea, subdioecy.

\section{Introduetion}

Gynodioecy, the occurrence of females and hermaphrodites in a population, may be an early stage in the evolution of dioecy (Lloyd, 1976) but the argument has been difficult to frame in genetic terms. The difficulty arises because of the complex and poorly understood genetic mechanisms that underlie sex expression in most of the gynodioecious species that have been studied (Charlesworth, 1981). Available studies have usually demonstrated complex interactions between cytoplasmic factors leading to male sterility and nuclear genes that restore male fertility (Frank, 1989). The widespread occurrence of cytoplasmic factors among gynodioecious species has led to the view that nuclear control of male sterility is rare or non-existent (Gouyon \& Couvet, 1985), although there have been a few demonstrations of nuclear control of male sterility (Kohn, 1988; Connor \& Charlesworth, 1989).

Theoretical arguments have demonstrated the importance of cytoplasmic versus nuclear control of male sterility in the evolution of gynodioecy and dioecy. Cytoplasmically induced male sterility is favourable for the spread of females in populations but not the evolution of full dioecy (Charlesworth \&
Ganders, 1979; Charlesworth, 1981; Charlesworth, 1984). The rarity of dioecy in some plant families where gynodioecy is widespread and under partial cytoplasmic control (e.g. Lamiaceae; Darwin, 1877; Kheyr-Pour, 1981; Couvet et al., 1986) provides circumstantial evidence for the stability of gynodioecy. In contrast, if control of male sterility is nuclear, the frequency of females is likely to increase rapidly (Ross, 1978; Charlesworth, 1981). In these populations, high female frequency will lead to selection for increased male function in hermaphrodites, and eventually the evolution of subdioecy (males, females, and hermaphrodites) and full dioecy (males and females only; Charlesworth \& Charlesworth, 1978). When control of male sterility is through nuclear genes, gynodioecy and subdioecy may be transitory phases rapidly supplanted by full dioecy (Charlesworth, 1984).

The endemic Hawaiian genus Schiedea (Caryophyllaceae) provides a good opportunity to study the genetic basis of male sterility, and the role of nuclear versus cytoplasmic control in the evolution of full dioecy. Dicliny (including gynodioecy, subdioecy, and dioecy) is found in eight of the 22 species of Schiedea (Weller et al., 1990). The four species in the closely related Alsinidendron are hermaphroditic. All 
apparent stages in the evolution of dioecy are found in Schiedea, ranging from gynodioecious species with as low as 12-13 per cent females in populations, to species that are fully dioecious. The occurrence of gynodioecy in the same genus as dioecy strongly suggests that the dioecious species went through gynodioecious stages in their evolutionary past. The pattern of breeding system diversity in Schiedea also suggests that control of male sterility is likely to be through nuclear genes, as two species are fully dioecious. The variability of diclinous breeding systems in Schiedea may result from the apparently recent evolution of dicliny (Weller et al, 1990). As a consequence, Schiedea may represent a unique window on evolutionary processes associated with the spread of male sterility in populations.

In order to detect the presence of cytoplasmic factors, the crossing strategy included intergeneric, interspecific, interpopulational, and intrapopulational crosses. Crosses among populations often reveal the presence of cytoplasmic factors that cannot be detected using intrapopulational crosses (Kheyr-Pour, 1981; Gouyon \& Couvet, 1985). Interspecific and intergeneric crosses among Schiedea and the closely related Alsinidendron produce vigorous, and in many cases highly fertile hybrids, which allow tests for the occurrence of differentiated cytoplasm among divergent populations. Reciprocal crosses were carried out in a large number of cases because of their value for detecting cytoplasmic differences among populations (Kheyr-Pour, 1981). Crosses included hermaphroditic and diclinous species, to identify the heterogametic sex and dominance relationships. Intrapopulational crosses and self-pollinations were carried out to confirm interpretations based on interspecific crosses. Segregations from naturally pollinated gynodioecious and subdioecious species were evaluated in light of hypotheses based on controlled crosses.

\section{Materials and methods}

All control led crosses were made under greenhouse conditions. Seventeen of the 21 extant species of Schiedea and Alsinidendron were used for interspecific and intergeneric crosses, including all eight diclinous species of Schiedea (Tables 1 and 2). Plants used as maternal parents in interspecific crosses were usually females (plants with pistillate flowers) from diclinous populations. These plants were isolated from potential pollen donors before crosses were made. When hermaphroditic individuals (plants with perfect flowers) were used as maternal parents flowers were emasculated before another dehiscence. Crosses were casried out with fine forceps; when paternal parents were diclinous species with compact inflorescences ( $S$. globosa, $S$. kealiae, and $S$ apokremnos), the entire inflorescence was rubbed against the receptive stigmas of female flowers. In several cases crosses were repeated using different individuals of the same species. Reciprocal (bi-directional) crosses were made to determine whether the direction of cross had any effect on segregations: however, dicliny prevented use of the same individuals as female and male parents in most crosses. For several species intraspecific crosses were made for comparison with interspecific crosses. Seeds were collected when ripe, approximately 1 month after pollination, and planted approximately 6 months later following a period of dormancy. Approximately 30 individuals were raised to maturity for most crosses and scored for sex expression. Sexes were scored as female versus males + hermaphrodites. No attempt was made to distinguish between hermaphrodites and males of interspecific hybrids because of the difficulty in determining visually whether stigmas were functional.

Intraspecific crosses and self pollinations were carried out for Schiedea salicaria and $S$. adamantis, two gynodioecious species. Plants used for crosses of $S$. salicaria were collected from the field, or raised from seed collected from naturally pollinated females and hermaphrodites found in two natural populations occurring about $1 \mathrm{~km}$ apart on West Maui. Females occur at a frequency of 12-13 per cent in these populations (Weller et al., 1990). Eleven progeny (1.5 per cent) failed to flower by the end of the experiment and were discarded. Because of indications of sex lability among female progeny of $S$. salicaria, questionable individuals were saved and rescored for sex at least once. Individuals of $S$. adamantis grown from cuttings collected at Diamond Head Crater on O'ahu, the only known population of this species, were used in crosses and self pollinations. The frequency of females in this population is 41 per cent.

Sex expression was investigated among the progeny of naturally pollinated individuals of gynodioecious $S$. salicaria, subdioecious $S$. globosa, and hermaphroditic S. lydgatei. Sex of parental individuals was determined in the field, and sex ratios among the progeny were interpreted in light of results from controlled crosses. Progeny were raised from seeds collected from 2 years for $S$. salicaria, and a single year for $S$. globosa and $S$. lydgatei. Progeny of gynodioecious $S$. salicaria were scored as females of hermaphrodites. Because of the sex lability noted among progeny from controlled crosses of $S$. salicaria, individuals raised from the second year of seed collections were saved and rescored for sex at least once. Progeny of subdioecious $S$. globosa were scored as females, males, or herma- 
Table 1 Sex ratios in progeny of intra- and interspecific crosses using gynodioecious $(G$,), subdioecious (SubD), and dioecious (D) species. The sex of the individual used in the cross $(\mathrm{F}, \mathrm{M}$, or $\mathrm{H})$ follows the breeding system designation. Identification numbers following species names refer to specific individuals in populations, except where only three digits are shown. In this case, two to three individuals from a population were used as male parents. Totals are shown for progeny having the same maternal parent

\begin{tabular}{|c|c|c|c|}
\hline \multirow[b]{2}{*}{ Female parent } & \multirow[b]{2}{*}{$\times$ Male parent } & \multicolumn{2}{|c|}{ Sex of offspring } \\
\hline & & Female & $\begin{array}{l}\text { Male }+ \\
\text { hermaphrodite }\end{array}$ \\
\hline S. adamantis $847-\mathrm{B}(\mathrm{G}-\mathrm{F})$ & $\times S$. adamantis $847-5(\mathrm{G}-\mathrm{H})$ & 10 & 21 \\
\hline S. adamantis $847-\mathrm{B}(\mathrm{G}-\mathrm{F})$ & S. globosa 844-12-3 (SubD-M) & 14 & 15 \\
\hline S. adamanis 847-B (G-F) & $S$ globosa $844-12-4$ (SubD-M) & 22 & 9 \\
\hline S. adamantis $847-\mathrm{B}(\mathrm{G}-\mathrm{F})$ & S. kealiae $791-14$ (SubD-M) & 14 & 16 \\
\hline S. adamantis $847-\mathrm{B}$ (G-F) & S. kealiae $791-16$ (SubD-H) & 17 & 14 \\
\hline S. adamantis $847-\mathrm{B}(\mathrm{G}-\mathrm{F})$ & S. ligustrina $846(\mathrm{D}-\mathrm{M})$ & 12 & 14 \\
\hline S. adamantis $847-\mathrm{B}(\mathrm{G}-\mathrm{F})$ & S. mannii 793-1 (SubD-M) & 13 & 14 \\
\hline \multicolumn{2}{|l|}{ Total } & 102 & 103 \\
\hline \multicolumn{2}{|c|}{ S. globosa 844-4-59 (SubD-F) $\times$ S. adamantis 847-1 (G-H) } & 19 & 12 \\
\hline$S$, globosa 844-4-59 (SubD-F) & S. apokremnos $865(\mathrm{G}-\mathrm{H})$ & 4 & 4 \\
\hline S. globosa 844-4-59 (SubD-F) & S. globosa 844 12-11 (SubD-M) & 15 & 16 \\
\hline S. globosa $844-4-59$ (SubD-F) & S. kealine 791-1 (SubD-H) & 16 & 13 \\
\hline S. globosa 844-4-59 (SubD-F) & S. ligustrina 846 (D-M) & 7 & 7 \\
\hline S. globosa 844-4-59 (SubD-F) & S. spergulina $863(\mathrm{D}-\mathrm{M})$ & 3 & 6 \\
\hline \multicolumn{2}{|l|}{ Total } & 64 & 58 \\
\hline S. kealiae 791-7 (SubD-F) & $\times$ S. adamantis $847-1(\mathrm{G}-\mathrm{H})$ & 9 & 21 \\
\hline S. kealiae 791-7 (SubD-F) & S. globosa 844-4-22 (SubD-M) & 17 & 9 \\
\hline S, kealiae 791-7 (SubD-F) & S. kealiae 791-14 (SubD-M) & 11 & 13 \\
\hline S. kealiae $791-7$ (SubD-F) & S. ligustrina $846(\mathrm{D}-\mathrm{M})$ & 15 & 10 \\
\hline S. kealiae 791-7 (SubD-F) & S. mannii 793-1 (SubD-M) & 2 & 3 \\
\hline S. keatiae 791-7 (SubD-F) & S. spergutina 863-6(D-M) & 3 & 2 \\
\hline \multicolumn{2}{|l|}{ Total } & 55 & 65 \\
\hline
\end{tabular}

phrodites. Hermaphrodites, which for $S$. globosa are defined as individuals producing staminate and pistillate flowers, possess small numbers of pistillate flowers, and were detected by rescoring at least once. Progeny of hermaphroditic $S$. lydgatei were either pistillate or hermaphroditic. Potential sex lability was detected by scoring for sex on two occasions. Expected and observed segregations were compared using $G$ tests; $G_{\mathrm{H}}$ and $G_{\mathrm{P}}$ refer to $G$ tests for heterogeneity and pooled data, respectively (Sokal \& Rohlf, 1981). $G$ values with a probability of 0.05 or less were considered significant. For interspecific crosses using $S$. globosa and $S$. kealiae as seed parents, intraspecific crosses of female and heterozygous hermaphrodites of $S$. salicaria, and selfs of heterozygous hermaphrodites of $S$. salicaria, progeny were not included in the stati- stical analysis when the expected results were less than 5 .

\section{Results}

\section{Sex expression in progeny of interspecific crosses}

Interspecific crosses produced two segregation patterns. In the first of these patterns (Table 1), females were produced in the same numbers as males and hermaphrodites combined among progeny of three diclinous species used as female parents in crosses $(S$. adamantis, $G_{\mathrm{H}}=10.2$, d.f. $=6$, ns; $G_{\mathrm{P}}=0.005$, d.f. $=1$, ns; $S$. globosa, $G_{\mathrm{H}}=1.16$, d.f. $=3$, ns; $G_{\mathrm{P}}=0.764$, d.f. $=1$, ns; $S$. kealiae, $G_{\mathrm{H}}=8.60$, d.f. $=3, P<0.05$; 
Table 2 Sex ratios in progeny of interspecific or intergeneric crosses using hermaphroditic individuals of gynodioecious $\{S$. salicaria) or hermaphroditic species as one parent. Breeding system designations are followed by sex of individuals of diclinous species, as in Table 1. Identification numbers following species names refer to specific individuals in populations, except where only three digits are shown. In this case, two to three individuals from a population were used as either female or male parents

\begin{tabular}{|c|c|c|c|}
\hline \multirow[b]{2}{*}{ Female parent } & \multirow[b]{2}{*}{$\times$ Male parent } & \multicolumn{2}{|c|}{ Sex of offspring } \\
\hline & & Female & $\begin{array}{l}\text { Male }+ \\
\text { hermaphrodite }\end{array}$ \\
\hline A. lychonoides $867-16(\mathrm{H})$ & $\times$ S. globosa 844-12-4(SubD-M) & 0 & 11 \\
\hline A. lychnoides $867-31(\mathrm{H})$ & $\times S$, globosa 844-12-4 (SubD-M) & 0 & 18 \\
\hline S. adamantis 847-B (G-F) & $\times S$. hookeri $794-3\langle\mathbf{H}\rangle$ & 0 & 27 \\
\hline S. adamantis 847-B (G-F) & S. salicaria $842-1(\mathrm{G}-\mathrm{H})$ & 0 & 29 \\
\hline S. diffusa $848-1(\mathbf{H})$ & $\times$ S. globosa 844-5-11 (SubD-H) & 0 & 33 \\
\hline S. diffusa $848-1(\mathbf{H})$ & S. globosa 844-8-4 (SubD-M) & 0 & 7 \\
\hline S. diffusa $848-1(\mathbf{H})$ & S. adamantis $847-\mathrm{C}(\mathrm{G}-\mathrm{H})$ & 0 & 5 \\
\hline S. globosa 844-4-59 (SubD-F) & $\times$ A. lychnoides $867-31(\mathrm{H})$ & 0 & 14 \\
\hline S. globosa 844-4-59 (SubD-F) & A. bychnoides Alkali $(\mathrm{H})$ & 0 & 14 \\
\hline S. globosa 844-4-59 (SubD-F) & S. hookeri 794-1 (H) & 0 & 21 \\
\hline$S$ globosa 844-4-59 (SubD-F) & S. kaalae $881-1(\mathbf{H})$ & 0 & 22 \\
\hline S. globosa 844-4-59 (SubD-F) & S. menziesii $849(\mathrm{H})$ & 0 & 24 \\
\hline S. globosa 844-4-59(SubD-F) & S. nuttaltii $861-12(\mathrm{H})$ & 0 & 22 \\
\hline S. globosa 844-4-59 (SubD-F) & S. salicaria $842-1\langle\mathrm{G}-\mathrm{H}\rangle$ & 0 & 46 \\
\hline S. globosa 844-7-129 (SubD-F) & $\times$ A. lychnoides $867-31(\mathrm{H})$ & 0 & 22 \\
\hline S. globosa 844-7-129 (SubD-F) & A. lychnoides Alkali $(\mathrm{H})$ & 0 & 24 \\
\hline S. globosa 844-7-129 (SubD-F) & S. kaalae $881-1(\mathrm{H})$ & 1 & 12 \\
\hline S. globosa 844-7-129 (SubD-F) & S. membranacea $864(\mathrm{H})$ & 0 & 21 \\
\hline S. globosa $844-7-129$ (SubD-F) & S. menziesii $849\langle\mathrm{H}\rangle$ & 0 & 44 \\
\hline S. globosa 844-7-129 (SubD-F) & S. nuttallii $861-17(\mathrm{H})$ & 0 & 16 \\
\hline S. globosa 844-7-129 (SubD-F $\rangle$ & S. verticillata $880-1(\mathbf{H}\rangle$ & 0 & 20 \\
\hline S. globosa 844-91-2-23 (SubD-F) & $\times A$, trinerve Perlman $5448(\mathrm{H})$ & 0 & 13 \\
\hline S. hookeri $794(\mathbf{H})$ & $\times S$. salicaria $842(\mathrm{G}-\mathrm{H})$ & 0 & 10 \\
\hline S. kaalae $881-1(\mathrm{H})$ & $\times S$. membranacea $864-9(\mathrm{H})$ & 0 & 8 \\
\hline S. kealiae $791-6($ SubD-F $)$ & $\times S$. verticillata $880-1(\mathrm{H})$ & 0 & 22 \\
\hline S. kealiae 791-7 (SubD-F) & $\times$ S. hookeri $794-3(\mathbf{H})$ & 1 & 24 \\
\hline S. kealiae 791-7 (SubD-F) & S. kaalae $881-1(\mathrm{H})$ & 0 & 10 \\
\hline S. kealiae 791-7 (SubD-F) & S. menziesii $849\langle\mathrm{H}\rangle$ & 0 & 17 \\
\hline S. kealiae 791-7 (SubD-F) & S. nuttallii $861-17(\mathrm{H})$ & 0 & 8 \\
\hline S. kealiae 791-7 (SubD-F) & S. salicaria $842-2(\mathrm{G}-\mathrm{H}\rangle$ & 0 & 29 \\
\hline S. verticillata $880-1(\mathbf{H})$ & $\times$ S. kaalae $881-1(\mathbf{H})$ & 0 & 15 \\
\hline S. verticillata $880-1(\mathbf{H})$ & $\times$ S. globosa 844-12-5 (SubD-H) & 0 & 20 \\
\hline S. verticillata $880-1(\mathbf{H})$ & $\times$ S. globosa $844-12-10($ SubD-H $)$ & 0 & 24 \\
\hline S. verticillata $880-1(\mathrm{H})$ & $\times$ S. salicaria $842-8(\mathrm{G}-\mathrm{H})$ & 0 & 24 \\
\hline
\end{tabular}

$G_{\mathrm{p}}=0.009$, d.f. $=1$, ns $)$. Female parents in these crosses have either gynodioecious or subdioecious breeding systems; species used as male parents were gynodioecious, subdioecious or dioecious. The gynodioecious species used as male parents were $S$, apokremnos, where the frequency of females among progeny raised in the greenhouse was 41 per cent, and $S$. adamantis, where the frequency of females in the field is also 41 per cent. The segregation of equal numbers of females and males thermaphrodites indicates that one of the parents used in each cross was heterozygous at the sexdetermining locus.
Based on segregation patterns in progeny of hermaphroditic species, the male (or hermaphroditic) sex in diclinous species is likely to be heterogametic. When at least one parent in a cross was a hermaphroditic species, or a hermaphrodite of gynodioecious $S$. salicaria, only hermaphrodites + males were produced in the progeny (Table 2, note the appearance of one female in each of two crosses, interpreted as contamination). Exclusive production of hermaphrodites + males occurred regardless of the direction of the cross, and also carried across generic boundaries, i.e. hybrids of $S$. globosa with $A$. lychnoides and $A$. tri- 
nerve produced only hermaphrodites. The results are consistent with the hypothesis that the allele that determines hermaphroditism is homozygous in hermaphroditic species (and the hermaphroditic individual of $S$. salicaria used as a male parent), and dominant to the allele that governs expression of male sterility.

Interspecific crosses provided no evidence for cytoplasmic control of male sterility in Schiedea. Different cytotypes are characteristic of species with cytoplasmic control of male sterility (Frank, 1989), and crosses among populations are likely to lead to female excesses when mismatches of cytotypes and male fertilityrestoring factors occur. Despite the large number of species used in crosses of Schiedea and Alsinidendron, no female excesses were observed (Tables 1 and 2).
Furthermore, no differences were detected in reciprocal crosses between populations (Tables 1 and 2), a result consistent with the presence of uniform cytoplasm.

\section{Sex expression in progeny resulting from intraspecific crosses}

Results obtained from intraspecific crosses of $S$. salicaria were generally consistent with nuclear control of sex expression. Females crossed with hermaphroditic progeny raised from field-collected seed of female $S$. salicaria segregated females and hermaphrodites in approximately equal numbers $\left(G_{\mathrm{H}}=0.211\right.$, d.f. $=1$, ns; $G_{\mathrm{P}}=2.02$, d.f. $=1$, ns, Table $\left.3 \mathrm{a}\right)$, the expected result

Table 3 Sex ratios among progeny from controlled crosses of gynodioecious $S$, salicaria. Crosses are categorized by the most likely genetic categories of the parents, based on the progeny ratios

\begin{tabular}{lll}
\hline & Sex of offspring \\
\cline { 2 - 2 } Female parent $\times$ Male parent & Female Hermophrodite Mortality Total \\
\hline
\end{tabular}

(a) Female $\times$ heterozygous hermaphrodite

$\begin{array}{lrrrr}842-65-5 \times 842-4 & 10 & 7 & 1 & 18 \\ 842-103-15 \times 842-4 & 10 & 5 & 4 & 19 \\ 853-65-5 \times 853-102-2 & 5 & 1 & 2 & 8\end{array}$

(b) Heterozygous hermaphrodite $\times$ homozygous hermaphrodite (or reciprocal)

$\begin{array}{lllrrr}842-57-12 & \times 853-102-1 & 0 & 77 & 9 & 86 \\ 842-57-12 \times 853-33-3 & 1 & 7 & 0 & 8 \\ 853-33-20 \times 842-57-12 & 0 & 35 & 11 & 46 \\ 853-102-1 & \times 842-57-12 & 0 & 73 & 11 & 84\end{array}$

(c) Homozygous hermaphrodite selfed

$\begin{array}{lllll}842-57-12 \times \text { self } & 0 & 8 & 4 & 12\end{array}$

(d) Female $\times$ homozygous hermaphrodite

$\begin{array}{lrrrrr}842-65-5 & \times 842-5 & 4 & 26 & 9 & 39 \\ 842-65-5 & \times 842-2 & 1 & 24 & 5 & 30 \\ 842-9-17 & \times 842-2 & 0 & 5 & 0 & 5 \\ 853-103-15 \times 842-5 & 1 & 15 & 10 & 26 \\ 853-12-7 \times 842-5 & 0 & 13 & 11 & 24\end{array}$

(e) Heterozygous hermaphrodite selfed

\begin{tabular}{|c|c|c|c|c|}
\hline $842-46-24$ & $\times$ self & 7 & 8 & 11 \\
\hline $853-3-9$ & $X$ self & 3 & 6 & 3 \\
\hline $853-33-1$ & $x$ self & 1 & 3 & 1 \\
\hline $853-33-20$ & $\times$ self & 6 & 1 & 7 \\
\hline $853-46-23$ & $\times$ self & 3 & 9 & 17 \\
\hline $853-102-2$ & $X$ self & 30 & 30 & 18 \\
\hline $853-102-11$ & $\times$ self & 24 & 27 & 47 \\
\hline
\end{tabular}

(f) Heterozygous hermaphrodite $\times$ heterozygous hermaphrodite

\begin{tabular}{lllll}
$853-25-12 \times 853-102-1$ & 6 & 7 & 2 & 15 \\
\hline
\end{tabular}


because hermaphroditic progeny of females should be heterozygous.

A second category of hermaphrodites segregated very few females (7/290 surviving offspring; Table $3 \mathrm{~b}-\mathrm{d}$; ; these hermaphrodites are presumed to be homozygous at the sex-determining locus. One hermaphrodite (842-57-12) segregated virtually no females $\{1 / 193$, Table $3 b)$, with the direction of the cross having no effect on segregation partern. Self-pollination of 842-57-12 produced no females, although only eight progeny survived to flowering (Table $3 \mathrm{c}$ ). Two additional hermaphrodites (842-2 and 842-5) segregated very few females when crossed to females (Table 3d); these individuals also are presumed to be homozygous at the sex-determining locus. Six of the seven unexpected females that appeared were produced among the progeny of $842-5$, which suggests sex lability or contamination largely restricted to this family.

When selfed, hermaphroditic offspring of females segregated females and hermaphrodites, as expected if these individuals are heterozygotes (Table 3e). A similar result was obtained for one cross of two different heterozygous hermaphrodites (Table 3f; the small number of progeny precluded statistical analysis of the sex ratio). Selfs or crosses involving only heterozygotes should produce 3:1 ratios of hermaphrodites:females, an expectation clearly at variance with the results obtained for pooled data from selfs of $S$. salicaria $\left(G_{\mathrm{H}}=0.101\right.$, d.f. $=1, \mathrm{~ns} ; G_{\mathrm{p}}=28.7$, d.f. $=1$, $P<0.005)$. The mortality of seedlings produced through self-pollination was twice that from seedlings produced through outcrossing ( 38 per cent mortality for selfs, $n=286 ; 19$ per cent for outcrosses, $n=440$; $G=32.2$, d.f. $=1, P<0.005$ ), which may have contributed to the female bias.

Self-pollinations and crosses of hermaphrodites of $S$. adamantis yielded females and hermaphrodites, again indicating that the hermaphroditic sex is heterozygous (Table 4). Crosses between females and hermaphrodites also yielded fentales and hermaphrodites in an approximate $1: 1$ ratio (Table $4 ; G=1.60$, d.f. $=1$; $P>0.05\}$.

Table 4 Sex ratios among progeny from controlled crosses of gynodioecious $S$. adamantis

\section{Sex of offspring}

\begin{tabular}{lcc} 
Type of cross & Female & Hermaphrodite \\
\hline $\begin{array}{l}\text { Self-pollinations and crosses } \\
\text { among hermaphrodites }\end{array}$ & 4 & 8 \\
\begin{tabular}{l} 
Female $\times$ hermaphrodite \\
\hline
\end{tabular} & 12 & 19 \\
\hline
\end{tabular}

\section{Sex ratios in progeny of naturally pollinated}

S. salicaria, S. globosa, and S. lydgatei

Progeny raised from 11 female individuals of $S$. salicaria yielded 24 per cent females $(n=293$ progeny, Table 5). Fewer females were produced in the progeny of hermaphrodites ( 15 per cent, $n=670$ progeny). The majority (29/34) of hermaphroditic individuals of $S$. salicaria produced some females in their progeny (Table 5), which suggests that these hermaphrodites were heterozygous for male sterility. In most cases, however, the number of females was quite small (e.g. seven families had a single female among the progeny, and another seven families had two females in each set of progeny). Similar results were obtained for progeny raised from seeds collected 2 years later in the same population. There was no indication of sex lability in the second set of progeny, which was scored for sex on two occasions separated by $2-3$ months. The low frequency of females in S. salicaria in the field (12-13 per cent) indicates that most hermaphrodites should be homozygous at the sex-determining locus. The high frequency of apparently heterozygous hermaphrodites in the population is therefore surprising.

Among progeny of female $S$. globosa, 44.6 per cent of the offspring were female, 38.2 per cent were male, and 17.3 per cent were hermaphroditic (Table 6). The sex ratio is significantly biased towards males t hermaphrodites combined $(G=9.33$, d.f. $=1$, $P<0.005$, Table 6). No attempt was made to test for heterogeneity because many families contained few hermaphrodites. All six hermaphroditic families produced females and were heterozygous at the sex-determining locus. Hermaphrodites yielded an approximate $3: 1$ ratio of hermaphrodites + males:females $(G=1.73$, d.f. $=1 ; P>0.05)$, a result consistent with either 100 per cent selfing of heterozygous hermaphrodites or outcrossing to other heterozygous males or hermaphrodites. The actual selfing rate of hermaphrodites is intermediate between complete selfing and complete outcrossing (A. K. Sakai \& S. G. Weller, unpublished data). Heterozygous males (or hermaphrodites) are expected to predominate in S. globosa, because hermaphrodites are rare under field conditions and most offspring are produced from females (Weller \& Sakai, 1990).

The occurrence of hermaphroditic function in some heterozygous individuals of $S$ globosa is under environmental and genetic crontrol. Under uniform greenhouse conditions there was significant heterogeneity in the expression of hermaphroditism among maternal families grown from field-collected seed, which indicates that the degree of female function in hermaphrodites may be a quantitative trait (Weller \& 
Table 5 Sex ratios in progeny raised in the greenhouse from seeds of naturally pollinated S. salicaria (population 842) collected in 1987. Identification numbers of maternal parents are for permanently marked plants growing at the field site

\begin{tabular}{|c|c|c|}
\hline \multirow[b]{2}{*}{ Family } & \multicolumn{2}{|c|}{ Sex of offspring } \\
\hline & Female & Hermaphrodite \\
\hline \multicolumn{3}{|c|}{ Progeny raised from female parents } \\
\hline 9 & 10 & 38 \\
\hline 22 & 4 & 7 \\
\hline 46 & 2 & 18 \\
\hline 48 & 0 & 10 \\
\hline 65 & 18 & 27 \\
\hline 89 & 19 & 28 \\
\hline 107 & 6 & 21 \\
\hline 111 & 2 & 13 \\
\hline 129 & 1 & 13 \\
\hline 136 & 6 & 22 \\
\hline 137 & 3 & 25 \\
\hline Total & 71 & 222 \\
\hline \multicolumn{3}{|c|}{ Progeny raised from hermaphroditic parents } \\
\hline 20 & 3 & 8 \\
\hline 21 & 6 & 10 \\
\hline 22 & 4 & 7 \\
\hline 24 & 2 & 10 \\
\hline 35 & 4 & 8 \\
\hline 43 & 2 & 19 \\
\hline 52 & 1 & 46 \\
\hline 58 & 1 & 18 \\
\hline 60 & 0 & 9 \\
\hline 61 & 4 & 29 \\
\hline 62 & 0 & 17 \\
\hline 63 & 2 & 12 \\
\hline 64 & 3 & 8 \\
\hline 65 & 1 & 8 \\
\hline 67 & 6 & 16 \\
\hline 70 & 5 & 29 \\
\hline 74 & 1 & 7 \\
\hline 76 & 0 & 18 \\
\hline 78 & 13 & 28 \\
\hline 79 & 1 & 29 \\
\hline 81 & 2 & 33 \\
\hline 85 & 1 & 11 \\
\hline 99 & 2 & 16 \\
\hline 103 & 4 & 17 \\
\hline 106 & 5 & 22 \\
\hline 109 & 1 & 16 \\
\hline 110 & 2 & 11 \\
\hline 116 & 2 & 15 \\
\hline 121 & 7 & 33 \\
\hline 126 & 0 & 12 \\
\hline 127 & 3 & 5 \\
\hline 132 & 0 & 14 \\
\hline 134 & 3 & 17 \\
\hline 141 & 10 & 11 \\
\hline Total & 101 & 569 \\
\hline
\end{tabular}

Table 6 Sex ratios of progeny raised in the greenhouse from seeds of naturally pollinated S. globosa (population 844). Identification numbers of maternal parents are for permanently marked plants growing at the field site

\begin{tabular}{|c|c|c|c|}
\hline \multirow[b]{2}{*}{ Family } & \multicolumn{3}{|c|}{ Sex of offspring } \\
\hline & Female & Male & Hermaphroditic \\
\hline \multicolumn{4}{|c|}{ Progeny raised from female parents } \\
\hline 1 & 7 & 8 & 0 \\
\hline 2 & 7 & 8 & 0 \\
\hline 5 & 15 & 13 & 6 \\
\hline 18 & 5 & 9 & 2 \\
\hline 25 & 8 & 5 & 8 \\
\hline 27 & 6 & 9 & 4 \\
\hline 30 & 29 & 15 & 14 \\
\hline 43 & 42 & 15 & 0 \\
\hline 46 & 3 & 5 & 5 \\
\hline 49 & 8 & 6 & 5 \\
\hline 51 & 10 & 2 & 4 \\
\hline 62 & 27 & 18 & 10 \\
\hline 64 & 7 & 7 & 5 \\
\hline 68 & 26 & 32 & 24 \\
\hline 70 & 8 & 6 & 2 \\
\hline 76 & 7 & 5 & 4 \\
\hline 105 & 8 & 8 & 14 \\
\hline 118 & 9 & 8 & 1 \\
\hline 138 & 19 & 17 & 5 \\
\hline 150 & 29 & 31 & 3 \\
\hline 170 & 27 & 32 & 5 \\
\hline 172 & 9 & 11 & 4 \\
\hline 173 & 18 & 9 & 5 \\
\hline 202 & 13 & 15 & 6 \\
\hline 240 & 7 & 9 & 1 \\
\hline Total & 354 & 303 & 137 \\
\hline \multicolumn{4}{|c|}{ Progeny raised from hermaphroditic parents } \\
\hline 12 & 22 & 33 & 36 \\
\hline 19 & 4 & 3 & 13 \\
\hline 28 & 27 & 14 & 21 \\
\hline 91 & 20 & 52 & 23 \\
\hline 187 & 4 & 4 & 3 \\
\hline 212 & 8 & 2 & 11 \\
\hline Total & 85 & 108 & 107 \\
\hline
\end{tabular}

Sakai, 1990). Fifty per cent of the individuals scored as males in the field became hermaphroditic when grown in the greenhouse, which shows that sex expression also has a strong environmental component (Weller \& Sakai, 1990).

S. lydgatei, a strictly hermaphroditic species under field conditions, produced 1-4 female progeny in five of the 23 families raised from field-collected seed; average family size was 11.1 . All but one female were consistent in sex across scoring dates separated by 6 months. 


\section{Discussion}

Segregation patterns in interspecific and intergeneric crosses of Schiedea and Alsinidendron are largely consistent with nuclear control of sex expression, male heterogamety, and dominance of the allele that determines the male or hermaphroditic sex. Female-biased sex ratios, often characteristic when cytoplasmic factors control male sterility, were not found in any of the interspecific or intergeneric crosses. Because the use of the same female in combination with male or hermaphroditic individuals from many other populations increases the probability of detecting cytoplasmic factors, it seems apparent that Schiedea and Alsinidendron lack cytoplasmic variability.

Results from intraspecific crosses of $S$. salicaria conformed for the most part with those obtained from interspecific and intergeneric crosses. The appearance of small numbers of females in several of the controlled crosses, and in many of the progeny of hermaphrodites raised from field-collected seeds was puzzling, because many hermaphrodites should be homozygous at the sex-determining locus given the low frequency of females. Labile sex was noted in several cases but does not account for the appearance of females among the progeny of the majority of hermaphrodites in the field, assuming the single locus model is correct. The presence of these females may result from developmental instability associated with inbreeding (Schemske, 1983; Dudash, 1990). In Ipomopsis aggregata, which is normally hermaphroditic, inbreeding results in the production of pistillate individuals (Benjamin \& Hainsworth, 1986); in Nemophila menziesii selfing results in individuais with partial pollen abortion and incomplete anther dehiscence (Ganders, 1978). Selfing rates ( $\sim 50$ per cent; A. K. Sakai \& S. G. Weller, unpublished data) and inbreeding depression (Sakai et al., 1989) in S. salicaria are high enough to have a similar effect on sex expression, beyond the effect of the hypothesized single Mendelian locus that controls sex expression.

A second possibility that accounts for the appearance of a few females in the progeny of most hermaphrodites of $S$. salicaria is a mutation that results in male sterility at loci other than the main male sterility locus (D. Charlesworth, personal communication). The low fitness associated with the majority of these mutations may prevent their spread in the population. Mutations that result in male sterile individuals with low fitness may occur in $S$. lydgatei as well, which would explain the presence of male sterile individuals among greenhouse progeny but not in the field population.

The distribution of breeding systems in Schiedea and Alsinidendron is also suggestive of nuclear control of male sterility. Theoretical studies (Ross, 1978;
Charlesworth, 1981; Charlesworth, 1984) have shown that nuclear control should lead to the rapid evolution of dioecy, whereas cytoplasmic control of male sterility results in stable gynodioecy. Subdioecy and full dioecy are more common than gynodioecy in Schiedea. Of the eight diclinous species in the genus, three are gynodioecious (Weller et al., 1990), and the remaining diclinous species are either subdioecious or fully dioecious. Among the three gynodioecious species, the breeding system of $S$. adamantis, where females occur at a frequency of 41 per cent, shows features similar to subdioecy. Females of $S$. adamantis produce more capsules than hermaphrodites, and seeds of females weigh more and have higher germination rates than those of hermaphrodites (A. K. Sakai \& S. G. Weller, unpublished data). In contrast, hermaphrodites of $S$. salicaria, where the frequency of females is $12-13$ per cent, show little evidence of reduced female function (Weller \& Sakai, 1990). Gynodioecious breeding systems may represent a brief transitory phase in breeding system evolution in Schiedea, with full dioecy representing a stable end-point of the trajectory. Detection of the intermediate stages in Schiedea is probably fortuitous, resulting from the relatively recent adaptive radiation in the genus (Weller et al., 1990). In contrast to Schiedea, the occurrence of stable gynodioecy is typified by the Hawaiian Bidens, where 13 of the 27 taxa are gynodioecious, and control of male sterility is partially cytoplasmic (Sun, 1987). Among the Hawaiian Bidens, there is no indication that full dioecy may be evolving.

The genetic system that controls male sterility in Schiedea is considerably simpler than those that have been hypothesized for many other gynodioecious species (Ganders, 1978; Kheyr-Pour, 1981; Van Damme \& Van Delden, 1982; Van Damme, 1983; Sun, 1987). In these studies the interaction of cytoplasmic and nuclear-restoring factors (Couvet et al., 1986) undoubtedly contributes to the complexity of the gene interactions. In Phacelia linearis, a single nuclear factor appears to control male sterility, although cytoplasmic factors may vary among populations (Eckhart, 1990). A single nuclear factor appears to govern sex expression in Cucurbita foetidissima (Kohn, 1988), although in contrast to Schiedea, females of C. foetidissima are heterogametic. Connor and Charlesworth's (1989) conclusion that three nuclear loci govern male sterility in Cortaderia represents another study demonstrating nuclear control of male sterility in a gynodioecious species. As more studies become available, for species in genera where gynodioecy appears to be evolving toward dioecy (sensu Ross, 1978; Charleswotth, 1981), simpler nuclear systems may predominate.

Interspecific crosses of diclinous Schiedea species all 
resulted in segregation of females, which indicates that the genes controlling male sterility are allelic. Based on interspecific crosses, Sun (1987) reached a similar conclusion for the Hawaiian Bidens, and suggested that the 13 gynodioecious species of Bidens evolved from a single ancestral gynodioecious species. In contrast to Bidens, biogeographic evidence indicates that dicliny has evolved independently on three to six occasions in Schiedea (Weller et al., 1990). In each case, it appears that a mutation at the same locus is responsible for male sterility. Diclinous species of Schiedea all occur in dry habitats in Hawaii; hermaphroditic species for the most part are found in mesic or wet forest (Weller et al., 1990). This ecological correlation suggests that higher selfing rates and the subsequent expression of inbreeding depression, perhaps associated with loss of pollinators in dry habitats, may have led to the spread of male sterility in these populations.

\section{Acknowledgements}

We thank Tim Flynn, Derral Herbst, Bob Hobdy, Steve Perlman, and John Obata for providing seeds and help in locating populations. Kathleen Brum, Dorothea Harvey, Carol Rincon, Nichole Brough, and Mamie Mitchell cared for the plants in the greenhouse. Joanna Norman, Denise Porter, Steve Porter, Kurt Potgieter, and Melissa Yu assisted in carrying out crosses and scoring offspring. We thank Brian and Deborah Charlesworth for their encouragement, and Deborah Charlesworth and Steven Frank for manuscript review. This research was supported by the National Geographic Society (3643-87) and the National Science Foundation (BSR-8817616).

\section{References}

BENJAMIN, R. B. AND HAINSwORTH, F. R. 1986. Sex change with inbreeding: experiments on separate versus combined sexes. Evolution, 40, 843-855.

CHARLESWORTH, B. 1984. Genetic constraints in the evolution of plant reproductive systems. In: Gregorius, H.-R. (ed.) Lecture Notes in Biomathematics 60. Population genetics in forestry, Springer-Verlag, Berlin, pp. 155-179.

CHARLESWORTH, B. AND CHARLESWORTH, D. 1978. A model for the evolution of dioecy and gynodioecy. Am. Nat., 112, 975-997.

CHARLESWORTH, D. 1981. A further study of the problem of the maintenance of females in gynodioecious species. Heredity, 46, 27-39.

CHARLESWORTH, D. AND GANDERS, F. R. 1979. The population genetics of gynodioecy with cytoplasmic-genic malesterility. Heredity, 43, 213-218.

CONNOR, H. E. AND CHARLESWORTH, D, 1989. Genetics of male- sterility in gynodioecious Cortaderia (Gramineae). Heredify, 63, 373-382.

COUVET, D., BONNEMAISON, F. AND GOUYON, P.-H. 1986. The maintenance of females among hermaphrodites: the importance of nuclear-cytoplasmic interactions. Heredity, 57, 325-330.

DARWIN, C. 1877. The Different Forms of Flowers on Plants of the Same Species. Murray, London.

DUDASH, M. R. 1990. Relative fitness of selfed and outcrossed progeny in a self-compatible, protandrous species, Sabatia angularis L. (Gentianaceae): A comparison in three environments. Evolution, 44, 1129-1139.

ECKHART, V. 1990. Variation in the fitness consequences of gender in Phacelia linearis, a gynodioecious annual. Bull. Eco. Soc. Am., 71 (Suppl), 144.

FRANK, S. A. 1989. The evolutionary dynamics of cytoplasmic male sterility. Am. Nat., 133, 345-376.

GANDERS, F. R. 1978. The genetics and evolution of gynodioecy in Nemophila menziesii. Can. J. Bot., 56, 1400-1408.

GOUYON, P.-H. AND COUVET, D. 1985. Selfish cytoplasm and adaptation: variations in the reproductive system of thyme. In: Haeck, J. and Woldendorp, J. W. (eds), Structure and Functioning of Plant Populations 2, North-Holland Publishing Co., Amsterdam, pp. 299-319.

KHEYR-POUR, A. 1981. Wide nucleo-cytoplasmic polymorphism for male sterility in Origanum vulgare L. Heredity, 72, 45-51.

KoHN, 3. 1988. Why be female? Nature, 335, 431-433.

LUOYD, D. G. 1976. The transmission of genes via pollen and ovules in gynodioecious angiosperms. Theor. Pop. Biol., 9, 299-316.

ROSS, M. D. 1978 . The evolution of gynodioecy and subdioecy. Evolution, 32, 174-188.

SAKAl, A. K., KAROLY, K. AND WELLER, s, G. 1989. Inbreeding depression in Schieden globosa and S. salicaria (Carophyllaceae), subdioecious and gynodioecious Hawailan species. Am. J. Bot., 76, 437-444.

SCHEMSKE, D. W. 1983. Breeding system and habitat effects on fitness components in three neotropical Costus (Zingiberaceae). Evolution, 37, 523-539.

SOKAL, R. R. AND ROHLF, F. J. 1981, Biometry, 2nd edn. Freeman and Co., New York.

SuN, M. 1987. Genetics of gynodioecy in Hawailan Bidens (Asteraceae). Heredity, 59, 327-336.

VAN DAMME, J. M. M. 1983. Gynodioecy in Plantago lanceolata L. II Inheritance of three male sterility types. Heredity, $\mathbf{5 0}$, 253-273.

VAN DAMME, J. M. M. AND VAN DELDEN, w. 1982. Gynodioecy in Plantago lanceolata L. I. Polymorphism for plasmon type. Heredity, 49, 303-318.

WELLER, S. G., SAKAI, A. X., WAGNER, W. L. AND HERBST, D. R. 1990. Evolution of dioecy in Schiedea (Caryophyllaceae: Alsinoideae) in the Hawaiian Islands: Biogeographical and Ecological Factors. Syst. Bot., 15, 266-276.

WELLER, S. G. AND SAKAI, A. K. (1990). The evolution of dicliny in Schiedea (Caryophyllaceae), an endemic Hawaiian genus. Plant Sp. Biol., 5, 83-95. 